OPEN ACCESS

Edited by:

Petr Smýkal,

Palacký University, Olomouc, Czechia

Reviewed by:

Alina Tollenaere

INRA Centre Bretagne-Normandie,

France

Sarah Veronica Schiessl,

Justus-Liebig-Universität Giessen,

Germany

Pedro Manuel Reis Mendes-Moreira,

Instituto Politécnico de Coimbra,

Portugal

${ }^{*}$ Correspondence:

Melaku Gedi

m.gedil@cgiar.org

Abebe Menkir

a.menkir@cgiar.org

Specialty section:

This article was submitted to

Crop Science and Horticulture,

a section of the journal

Frontiers in Plant Science

Received: 08 January 2017

Accepted: 04 May 2017

Published: 22 May 2017

Citation:

Abdulmalik RO, Menkir A, Meseka SK, Unachukwu N, Ado SG, Olarewaju JD, Aba DA, Hearne $S$, Crossa J and Gedil M (2017) Genetic

Gains in Grain Yield of a Maize Population Improved through Marker Assisted Recurrent Selection under

Stress and Non-stress Conditions in West Africa. Front. Plant Sci. 8:841.

doi: 10.3389/fpls.2017.00841

\section{Genetic Gains in Grain Yield of a Maize Population Improved through Marker Assisted Recurrent Selection under Stress and Non-stress Conditions in West Africa}

\section{Rekiya O. Abdulmalik ${ }^{1,2}$, Abebe Menkir ${ }^{1 *}$, Silvestro K. Meseka ${ }^{1}$, Nnanna Unachukwu ${ }^{1}$, Shehu G. Ado' ${ }^{2}$, Joseph D. Olarewaju², Daniel A. Aba ${ }^{2}$, Sarah Hearne ${ }^{3}$, Jose Crossa ${ }^{3}$ and Melaku Gedil ${ }^{*}$}

\begin{abstract}
'Maize Improvement Program, International Institute of Tropical Agriculture, Ibadan, Nigeria, ${ }^{2}$ Department of Plant Science, Institute for Agricultural Research, Ahmadu Bello University, Zaria, Nigeria, ${ }^{3}$ International Maize and Wheat Improvement Center, Mexico City, Mexico
\end{abstract}

Marker-assisted recurrent selection (MARS) is a breeding method used to accumulate favorable alleles that for example confer tolerance to drought in inbred lines from several genomic regions within a single population. A bi-parental cross formed from two parents that combine resistance to Striga hermonthica with drought tolerance, which was improved through MARS, was used to assess changes in the frequency of favorable alleles and its impact on inbred line improvement. A total of 200 testcrosses of randomly selected $S_{1}$ lines derived from the original $\left(C_{0}\right)$ and advanced selection cycles of this bi-parental population, were evaluated under drought stress (DS) and well-watered (WW) conditions at Ikenne and under artificial Striga infestation at Abuja and Mokwa in Nigeria in 2014 and 2015. Also, 60 randomly selected $\mathrm{S}_{1}$ lines each derived from the four cycles $\left(\mathrm{C}_{0}, \mathrm{C}_{1}, \mathrm{C}_{2}, \mathrm{C}_{3}\right)$ were genotyped with 233 SNP markers using KASP assay. The results showed that the frequency of favorable alleles increased with MARS in the bi-parental population with none of the markers showing fixation. The gain in grain yield was not significant under DS condition due to the combined effect of DS and armyworm infestation in 2015. Because the parents used for developing the biparental cross combined tolerance to drought with resistance to Striga, improvement in grain yield under DS did not result in undesirable changes in resistance to the parasite in the bi-parental maize population improved through MARS. MARS increased the mean number of combinations of favorable alleles in $S_{1}$ lines from 114 in $C_{0}$ to 124 in $C_{3}$. The level of heterozygosity decreased by $15 \%$, while homozygosity increased by $13 \%$ due to the loss of some genotypes in the population. This study demonstrated the effectiveness of MARS in increasing the frequency of favorable alleles for tolerance to drought without disrupting the level of resistance to Striga in a bi-parental population targeted as a source of improved maize inbred lines.

Keywords: maize, bi-parental cross, MARS, genetic gain, allele frequency 


\section{INTRODUCTION}

Maize (Zea mays L.) is an important food security and incomegenerating crop for millions of people in West and Central Africa (Adetimirin et al., 2008). Its production is limited by several biotic and abiotic factors including Striga hermonthica (Del) Benth, drought, declining soil fertility and susceptibility to pests and diseases (Odendo et al., 2001). Globally, about 160 million hectares of maize is grown under rain-fed conditions and annual yield losses attributed to drought are estimated at about 25\% (Edmeades, 2008). The losses are expected to be greater in tropical countries that rely on unpredictable and erratic rainfall (Mhike et al., 2012). The gap between potential yield and yield under drought stress (DS) is often large, but 20$25 \%$ of this gap could be eliminated by genetic improvement in drought tolerance and a further $20-25 \%$ by application of water-conserving agronomic practices (Edmeades, 2013). The remaining $50-60 \%$ can only be met by irrigation, when available and affordable (Edmeades et al., 2006). Drought alone causes an average yield loss of about 17-60\% (Edmeades et al., 1999), while Striga causes an estimated yield loss of about $10-100 \%$ under severe infestation (Lagoke et al., 1991; Odhiambo and Woomer, 2005). Armyworm (Spodoptera spp.) infestation occurs in maize from plant emergence to tasseling and silking. Losses due to the fall armyworm attack can reduce grain yield up to $34 \%$ (Cruz et al., 1999; Lima et al., 2010). Marker-assisted recurrent selection (MARS) in combination with high-throughput and precise phenotyping and year round nurseries can significantly accelerate the development of climate resilient maize germplasm and have been used to improve tolerance to drought (Xu et al., 2012; Prasanna et al., 2013).

Marker-assisted recurrent selection for quantitative traits has relied on identifying markers linked to quantitative trait loci (QTL). It involves improvement of an $\mathrm{F}_{2}$ population by one cycle of selection based on phenotypic data and marker scores followed by two to three cycles of marker based scores only (Johnson, 2001, 2004). Improving bi-parental maize populations for tolerance to stress through MARS is of major importance because it harnesses several QTLs carrying the most desirable combinations of favorable alleles using only significant markers to predict performance of the population (Meuwissen et al., 2001; Bohra, 2013). This procedure has been effective and superior to phenotypic selection (PS) by accumulating favorable alleles for multiple trait improvement in maize and other crops (Edwards and Johnson, 1994; Van Berloo and Stam, 1998, 2001; Charmet et al., 1999; Johnson, 2001, 2004; Yousef and Juvik, 2001; Eathington et al., 2007; Crossa et al., 2013, Massman et al., 2013).

Assessment of the changes in the frequency of favorable alleles within a bi-parental population improved by MARS would provide information on specific genomic regions that have responded to selection (Frascaroli and Landi, 1998). In addition, assessment of genetic gains in breeding program provides an opportunity to critically analyze efficiency and plan new actions and strategies. Realized progress with any breeding scheme, however, depends largely upon the ability of the breeders to identify superior genotypes and the precision of experimentation
(Khalil et al., 2010). Xu et al. (2012) proposed MARS as an effective tool to breed for complex traits because it enables the harnessing of those genes or QTL exhibiting minor effects on the phenotype. Edwards and Johnson (1994) studied the changes in frequency of favorable alleles in sweet corn $\mathrm{F}_{2}$ MARS population and observed an increase in the frequency of the favorable alleles from 0.50 to $\geq 0.80$ at 11 out of 35 markers used and one marker locus in the population became fixed for the favorable allele. Bernardo and Mayor (2009) observed an increase in the frequency of favorable alleles for grain yield from $\mathrm{C}_{0}(0.50)$ to $\mathrm{C}_{2}(0.65)$ in a double haploid $(\mathrm{DH})$ population improved by MARS. Recent studies (Semagn et al., 2015; Beyene et al., 2016a) have highlighted improved genetic gains in grain yield of tropical maize populations using MARS under DS. Semagn et al. (2015) reported an average gain of $184 \mathrm{~kg} \mathrm{ha}^{-1} \mathrm{cycle}^{-1}$ under WW and $45 \mathrm{~kg} \mathrm{ha}^{-1}$ under DS conditions in bi-parental maize populations, whereas Beyene et al. (2016a) reported an average gain of $105 \mathrm{~kg} \mathrm{ha}^{-1}$ year $^{-1}$ under well-watered (WW) and $51 \mathrm{~kg}$ $\mathrm{ha}^{-1}$ year $^{-1}$ under DS.

Maize breeders at the International Institute of Tropical Agriculture (IITA) developed a bi-parental maize population from elite inbred parents with combined tolerance to drought and resistance to $S$. hermonthica. The focus of the breeding activities was to improve the population for tolerance to drought in order to extract superior inbred lines with enhanced recombination of favorable alleles originating from both parents. The bi-parental population was improved through three cycles of marker assisted recurrent selection under DS condition. However, studies have not been conducted to assess genetic gains in tolerance to drought and changes in the frequency of favorable alleles that accrued under drought stressed conditions in this population. Also, assessment of the performance of progenies derived from improved cycles of this population under S. hermonthica infestation as a non-target environment is important to determine the effect of parental selection on grain yield and resistance to the parasite. This study was therefore, conducted to assess (i) genetic gains in grain yield under DS and WW conditions, (ii) the potential impact of parental selection on non-target traits under Striga infested condition in a bi-parental population improved with MARS, and (iii) the associated changes in the frequency and number of favorable alleles using SNP markers.

\section{MATERIALS AND METHODS}

\section{Development of MARS Population, Phenotyping and Genotyping of $\mathbf{F}_{\mathbf{2}: 3}$}

The population targeted for MARS in the study was derived from a cross between two elite Striga resistant inbred lines (Acr.Syn$\left.\mathrm{W}-\mathrm{S}_{2}-173-\mathrm{B}^{*} 4\right)$ and (TZLComp. $\left.1 \mathrm{C}_{4}-\mathrm{S}_{1}-37-5-\mathrm{B}^{*} 3\right)$, that are also tolerant to drought and resistant to the major lowland foliar diseases. The $F_{1}$ was selfed to generate $F_{2}$ bulk seeds, which were grown in 50 rows of $5 \mathrm{~m}$ length spaced $0.75 \mathrm{~m}$ apart to generate $300 \mathrm{~F}_{2: 3}$ lines $\left(\mathrm{F}_{2}\right.$ derived populations in $\left.\mathrm{F}_{3}\right)$. A total of $250 \mathrm{~F}_{2: 3}$ lines from this population were planted each in a row and crossed to an inbred tester from an opposite heterotic group. 
The testcrosses were evaluated under DS and WW conditions at Ikenne during the dry season (Supplementary Figure S1).

Marker effects of the genotyped $250 \mathrm{~F}_{2: 3}$ lines were calculated using the best linear unbiased prediction (BLUP) model (Meuwissen et al., 2001), which permitted predicting genomic estimated breeding value (GEBV) (Henderson, 1975; Gianola and Fernando, 1986). The GEBV was calculated per marker across all the lines derived from $\mathrm{C}_{0}$ using the BLUP values. Each line was scored 0 or 1 based on the presence or absence of parental allele. The BLUP value per marker was multiplied by the marker score of each line and the resultant values per line were the GEBVs. Significant markers on each chromosome were identified by backward elimination. A relaxed significance level $(P=0.10)$, which has been found desirable to maximize the response to MARS (Hospital et al., 1997; Johnson, 2001) was used. Selection at $C_{1}$ was based on marker used to calculate GEBV which is the sum of all marker effects included in the model for an individual. The selected $\mathrm{C}_{0}$ lines were ranked according to their GEBV and $10 \%$ of the $S_{1}$ lines with the highest GEBV were planted ear-torow and inter-crossed. Bulk pollen collected from 10 plants in each line was used for inter-crossing with other lines. Four ears were harvested in each row and shelled to obtain more than 100 seeds per ear. Equal amounts of seed were taken at random from each ear to form a bulk of the new cycle $\left(C_{1}\right)$ for planting. Leaf samples were collected from each of the plants for genotyping at LGC Genomics using the full complement of SNPs originally used for genotyping the $C_{0}$ populations. The top $10 \%$ of the $\mathrm{C}_{1}$ individuals were selected based on GEBV and intermated to form $\mathrm{C}_{2}$ as described above and repeated to form $\mathrm{C}_{3}$. All recombination were conducted at IITA, Ibadan in Nigeria.

\section{Formation of Testcrosses for Phenotypic Evaluation}

In 2013 , the original $\left(C_{0}\right)$ and advanced selection cycles $\left(C_{1}, C_{2}\right.$, and $\mathrm{C}_{3}$ ) of the MARS population were planted at Ibadan each in 60 rows of $5 \mathrm{~m}$ length spaced $0.75 \mathrm{~m}$ apart. Several plants were self-pollinated and 120 to $150 \mathrm{~S}_{1}$ lines were harvested from each selection cycle and retained. Amongst these, $60 \mathrm{~S}_{1}$ lines were randomly selected and were planted along with parental lines of the bi-parental cross and an inbred tester (TZISTR1138) at Ibadan in 2013 to generate testcrosses. The $\mathrm{S}_{1}$ lines were used as female parents, whereas the inbred tester was used as the male parent. Bulk pollen collected from the male parent was used to pollinate the emerged silks of several plants in each $S_{1}$ lines. The ears from each testcross were harvested and dried to $15 \%$ moisture content and shelled.

\section{Selection of Markers}

A final set of 275 SNPs were selected after rigorous screening of 1250 KASP assays developed by LGC Genomics (United Kingdom) by converting 1536 Illumina Golden Gate Array (Semagn et al., 2013). Two separate bulks of leaf from eight plants of each parent and one bulk of $F_{1}$ was genotyped with all 1247 SNP markers at LGC Genomics (formerly KBiosciences, United Kingdom). Of the 1247 markers run by LGC Genomics markers over a 1000 SNPs provided successful calling in one or both bulks of each parent. However, SNPs that were not uniform between the two bulks (one bulk homozygous and the other heterozygous; one has allele call and the other has no allele call) of the same parent or that gave no call in one or the other parent were eliminated. Likewise, SNPs that were heterozygous in either parent or homozygous in the $\mathrm{F}_{1} \mathrm{~s}$ were also excluded. Finally, 233 markers that are uniform and homozygous in the parents as well as polymorphic between the parents were used for genotypic selection in the MARS population (Supplementary Data 1).

\section{DNA Extraction and Genotyping}

Sixty randomly selected maize sample from each MARS cycles were used for DNA extraction. Leaf samples from each of the randomly selected $60 \mathrm{~S}_{1}$ lines planted to generate testcrosses and the two parents were collected 2 weeks after planting and transported to IITA Biosciences laboratory in Ibadan, Nigeria for DNA extraction. The samples were lyophilized to dry for about 3 days, then two tiny steel grinding balls $(2.4 \mathrm{~mm})$ were inserted into each extraction tubes. About 15-20 small leaf disk of each sample was punctured into extraction tubes, covered up and grounded into fine powder using the Geno Grinder-2000. Genomic DNA was extracted using a CTAB extraction protocol of Azmach et al. (2013). The clean pellets were dried by leaving the tubes open for at least an hour to get rid of all drops of ethanol. The dried DNA (pellet) in each tube was dissolved in $100 \mu \mathrm{l}$ solution of Rnase-DNase free water to get rid of all traces of RNA in the pellet. The purified genomic DNA was quantified in $\mathrm{ng} / \mathrm{ul}$ on a Nanodrop spectrophotometer and ran on $1 \%$ agarose gel to double check the DNA quality. Genomic DNA samples were lyophilized to dry powder and sent to LGC genomics (United Kingdom) for single nucleotide polymorphism (SNP) genotyping on Kbiosciences' KASP assay platform (KBioscenceLGC Genomics) ${ }^{1}$. The SNP data obtained from this assay was used to assign genotype score to the population.

\section{Phenotypic Evaluation of Testcrosses}

An experiment consisting of 50 randomly selected testcrosses of $S_{1}$ lines from each of the four cycles of selection, along with testcrosses of each of the parental line of the bi-parental cross to the same tester $\left(\mathrm{P}_{1} \times \mathrm{T}, \mathrm{P}_{2} \times \mathrm{T}\right)$, a cross of the two parental lines $\left(\mathrm{P}_{1} \times \mathrm{P}_{2}\right)$ and standard hybrid checks $9022-13$ and 8338-1 were evaluated under DS and WW conditions at Ikenne $\left(6^{\circ} 53^{\prime} \mathrm{N}\right.$, $30^{\circ} 42^{\prime} \mathrm{E}, 60 \mathrm{~m}$ asl, $1200 \mathrm{~mm}$ annual rainfall) during the 2014 and 2015 dry seasons. The testcrosses were arranged in a $41 \times 5$ alpha lattice design with two replications and were planted in single rows of $5 \mathrm{~m}$ long with $0.75 \mathrm{~m}$ space between rows and $0.25 \mathrm{~m}$ spacing between plants within a row (Abdulmalik et al., 2016). In the DS trial, DS was imposed by withdrawing irrigation water from 5 weeks after planting through harvest, whereas the WW trial received irrigation until physiological maturity. NPK 15:15:15 fertilizer was applied at the rate of $60 \mathrm{~kg} \mathrm{~N} \mathrm{ha}^{-1}, 60 \mathrm{~kg}$ $\mathrm{P} \mathrm{ha}^{-1}$, and $60 \mathrm{~kg} \mathrm{~K} \mathrm{ha}^{-1}$, at planting and an additional $60 \mathrm{~kg}$ $\mathrm{N} \mathrm{ha}^{-1}$ was applied 4 weeks later. In each trial, gramoxone and atrazine were applied as pre-emergence herbicides at $5.01 \mathrm{ha}^{-1}$.

\footnotetext{
${ }^{1}$ http://www.kbioscience.co.uk/
} 
Subsequently, manual weeding was done to keep the experiments weed-free.

The testcrosses were also evaluated under Striga infestation at Abuja $\left(9^{\circ} 16^{\prime} \mathrm{N}, 7^{\circ} 20^{\prime} \mathrm{E}, 300 \mathrm{~m}\right.$ asl, $1500 \mathrm{~mm}$ annual rainfall) and Mokwa $\left(9^{\circ} 18^{\prime} \mathrm{N}, 5^{\circ} 04^{\prime} \mathrm{E}, 457 \mathrm{~m}\right.$ asl, $1100 \mathrm{~mm}$ annual rainfall) for 2 years. The $S$. hermonthica seeds for infestation were mixed with fine sand in the ratio of 1:99 by weight and about 5,000 germinable Striga seeds were placed in each planting hills as described by Kim (1991). NPK 15:15:15 fertilizer was applied at the rate of $30 \mathrm{~kg} \mathrm{~N} \mathrm{ha}^{-1}$ at planting, and an additional $30 \mathrm{~kg} \mathrm{~N} \mathrm{ha}{ }^{-1}$ was applied 4 weeks after planting. The $\mathrm{N}$ rate, which was only half the recommended rate for maize in the savannas of Nigeria, was used to ensure optimal development of S. hermonthica that allowed differentiation among testcrosses for Striga damage rating (SDR) and ensured a minimum of 50\% yield reduction under infestation. Weeds other than Striga were removed by hand throughout the planting season.

\section{Data Collection}

Data was collected for grain yield, days to silking, anthesis-silking interval (ASI), plant height, ear aspect (EASP), plant aspect (PASP), and leaf senescence (SEN), SDR at 8 and 10 weeks after planting and number of emerged Striga plants (ESP). Days to silking was recorded as the number of days from planting to when $50 \%$ of the plants showed emerged silks. ASI was computed as the interval in days between silking and anthesis. Plant height was measured as the distance from the base of the plant to the height of the first tassel branch. EASP was also visually rated on a scale of 1 to 5 , where $1=$ clean, uniform, large, and wellfilled ears and $5=$ rotten, variable, small, and partially filled ears. PASP was rated on a scale of 1 to 5 , where $1=$ excellent overall phenotypic appeal and $5=$ poor overall phenotypic appeal. SEN was scored on a scale of 1 to 9 , where $1=$ almost all leaves green and $9=$ virtually all leaves dead. SDR was recorded on a scale of 1-9 (Kim, 1991) at 8 and 10 weeks after planting, where $1=$ no damage (highly resistant), $9=$ severe damage (highly susceptible). Number of ESP was counted at 8 and 10 weeks after planting. All ears harvested from each plot were shelled to determine percentage moisture and grain yield adjusted to $15 \%$ moisture was computed from the shelled grain weight.

Percentage yield loss $=$ yield of $(\mathrm{WW}-\mathrm{DS}) / \mathrm{WW} * 100$

\section{Statistical Analysis}

Analysis of variance (ANOVA) combined over years for all traits measured was conducted with PROC GLM in SAS using a RANDOM statement with the TEST option (SAS Institute, 2009). Independent ANOVA were conducted for data collected under DS, WW, and Striga infested conditions. Years, environments, replications, and incomplete blocks were considered as random effects whereas selection cycles and testcross within cycles were considered as a fixed effect. The significance of mean squares for the main and interaction effects were tested using the appropriate mean squares, obtained from the RANDOM option in SAS (SAS Institute, 2009).

For each trait, cycle means across environment were regressed as dependent variables on cycle numbers (0-3) as independent variables. The coefficient of linear regression ( $b$-value) provided an estimate of the gain per cycle, which was divided by the intercept and multiplied by 100 to obtain the percent response per cycle.

Favorable alleles are alleles that have a positive effect on the trait under selection for higher values and negative effect on the trait under selection for lower values. The favorable allele of each marker was determined using the coded marker scores -1 or 1 that was used to represent each parent. As the target trait was grain yield and alleles were expected to have a positive effect on it, the parent with the positive marker score was chosen as the favorable parent. The mean change in the frequency of favorable alleles was calculated for each cycle for all markers using the Power Marker (v3.25) software. The mean, minimum, maximum, skewness, kurtosis, and standard error of the frequency of favorable alleles were calculated using the PROC UNIVARIATE procedure in SAS version 9.3 (SAS Institute, 2009). The minor allele frequency, inbreeding coefficient, heterozygosity, homozygosity, number of effective alleles, genotype lost, and genotype gained were calculated using the Power Marker (v3.25) software.

\section{RESULTS}

\section{Performance of Testcrosses of $\mathrm{S}_{1}$ Lines under Drought Stress and Well-Watered Conditions}

In the combined ANOVA, year was a significant source of variation for all measured traits except ASI, plant height, PASP, SEN under DS and ASI, and EASP under WW conditions (Table 1). The variation of testcrosses within cycle was highly significant for days to silking and SEN under DS and days to silking, ASI and plant height under WW conditions. Year $\times$ testcross interaction was significant only for days to silking under both DS and WW conditions (Table 1).

Significant mean squares were recorded among selection cycles for grain yield, days to silking, and plant height under Striga infested condition (Table not included). Testcrosses within cycles were significant for all traits except for EASP and SDR at 8 weeks after planting. Environment $\times$ testcross interaction was significant for days to silking and SDR at 8 weeks after planting, while environment $\times$ cycle interaction was not significant for the remaining other measured traits.

\section{Genetic Gains of a Bi-parental Population Improved with MARS}

The testcrosses of MARS population sustained a $87 \%$ yield loss in 2015 due to severe damage by fall armyworm and an average of $73 \%$ in both years. The standard hybrid check (9022-13) also had the largest yield loss of $88 \%$ under DS, the highest days to silking, poorest PASP and shortest plants (Table 2). The highest grain yield was recorded at $\mathrm{C}_{3}$, which was significantly higher than the two standard check hybrids (9022-13 and 8338-1). The $\mathrm{C}_{3}$ yielded $13 \%$ more than $\mathrm{C}_{0}, 10 \%$ above $\mathrm{P}_{1} \mathrm{xT}$ and $44 \%$ more than $8338-1$ (Table 2). The $\mathrm{C}_{3}$ out yielded the base population by $163 \mathrm{~kg} \mathrm{ha}^{-1}$ 
TABLE 1 | Combined mean squares from analysis of variance for grain yield and other agronomic traits of a population improved with MARS under drought stress and well-watered conditions at Ikenne in 2014 and 2015.

\begin{tabular}{|c|c|c|c|c|c|c|c|c|}
\hline Source & df & $\begin{array}{l}\text { Grain yield } \\
\left(\mathrm{kg} \mathrm{ha}^{-1}\right)\end{array}$ & $\begin{array}{l}\text { Days to } \\
\text { silking }\end{array}$ & ASI & $\begin{array}{l}\text { Plant height } \\
\text { (cm) }\end{array}$ & Ear aspect (1-5) & Plant aspect (1-5) & $\begin{array}{l}\text { Leaf senescence } \\
\qquad(1-9)\end{array}$ \\
\hline \multicolumn{9}{|l|}{ Drought stress } \\
\hline Year & 1 & $503468519^{* * *}$ & $3738.9^{* *}$ & 96.2 & 71103 & $22.7^{*}$ & 7.1 & 23.2 \\
\hline Rep (year) & 2 & 1095999 & $46.5^{* * *}$ & $29.6^{*}$ & $27823^{* * *}$ & $1.2^{*}$ & 1.3 & 2.6 \\
\hline Block (rep*year) & 160 & $347250 * * *$ & $4.9 * * *$ & $2.0^{* *}$ & $769^{* * *}$ & $0.3^{* * *}$ & $0.4^{* * *}$ & $1.1^{* * *}$ \\
\hline Cycle & 3 & 609210 & 1.2 & 0.6 & 512 & 0.3 & $1.4^{* * *}$ & 1.8 \\
\hline Testcross (cycle) & 196 & 173602 & $6.1^{* * *}$ & 1.6 & 194 & 0.1 & 0.2 & $0.8^{* * *}$ \\
\hline Year*cycle & 3 & 126009 & 1.2 & 0.6 & 277 & 0.1 & 0.2 & 1.4 \\
\hline Year*testcross (cycle) & 196 & 164532 & $2.79^{*}$ & 1.4 & 160 & 0.1 & 0.1 & 0.5 \\
\hline Error & 238 & 154694 & 2.2 & 1.5 & 161 & 0.1 & 0.2 & 0.6 \\
\hline \multicolumn{9}{|l|}{ Well-watered } \\
\hline Year & 1 & $270273062^{* * *}$ & $1055.7^{*}$ & 0.3 & $61347.2^{* * *}$ & 3.0 & $55.2^{* * *}$ & \\
\hline Rep (year) & 2 & 543111 & 4.9 & 0.8 & 203.8 & 0.2 & 0.0 & \\
\hline Block (rep*year) & 160 & $1137466^{* * *}$ & $3.4^{* * *}$ & 0.4 & $348.2^{* * *}$ & $0.2^{* * *}$ & $0.2^{* * *}$ & \\
\hline Cycle & 3 & 181768 & 2.4 & 0.4 & 201.7 & 0.1 & 0.1 & \\
\hline Testcross (cycle) & 196 & 842886 & $5.4^{* * *}$ & $0.6^{* * *}$ & $192.8^{* * *}$ & 0.1 & 0.2 & \\
\hline Year* cycle & 3 & 308202 & 0.9 & 0.6 & 109.6 & 0.2 & 0.1 & \\
\hline Year*testcross (cycle) & 196 & 808615 & $2.3^{*}$ & 0.4 & 104.2 & 0.1 & 0.2 & \\
\hline Error & 238 & 697218 & 1.8 & 0.4 & 120.8 & 0.1 & 0.2 & \\
\hline
\end{tabular}

Significant at $* P \leq 0.05,{ }^{* *} P \leq 0.01$, and ${ }^{* * *} P \leq 0.001$ levels, respectively.

TABLE 2 | Means and genetic gains for grain yield and other agronomic traits of a population improved with MARS under drought stress and well-watered condition at Ikenne in 2014 and 2015.

\begin{tabular}{|c|c|c|c|c|c|c|c|c|c|c|c|c|c|}
\hline \multirow[b]{2}{*}{ Genotypes } & \multicolumn{2}{|c|}{$\begin{array}{l}\text { Grain yield } \\
\left(\mathbf{k g ~ h a}^{-1}\right)\end{array}$} & \multicolumn{2}{|c|}{$\begin{array}{c}\text { Days to } \\
\text { silking (days) }\end{array}$} & \multicolumn{2}{|c|}{ ASI } & \multicolumn{2}{|c|}{$\begin{array}{l}\text { Plant height } \\
\text { (cm) }\end{array}$} & \multicolumn{2}{|c|}{$\begin{array}{c}\text { Ear aspect } \\
(1-5)\end{array}$} & \multicolumn{2}{|c|}{$\begin{array}{c}\text { Plant aspect } \\
(1-5)\end{array}$} & \multirow{2}{*}{$\begin{array}{l}\text { Leaf Senescence } \\
(1-9)\end{array}$} \\
\hline & DS & WW & DS & WW & DS & WW & DS & WW & DS & WW & DS & WW & \\
\hline $\mathrm{C}_{0}$ & 1280 & 5013 & 58 & 58 & 3 & 2 & 151 & 201 & 3.4 & 2.8 & 3.0 & 2.5 & 6.3 \\
\hline $\mathrm{C}_{1}$ & 1387 & 5111 & 58 & 58 & 4 & 2 & 156 & 204 & 3.3 & 2.7 & 2.8 & 2.4 & 6.1 \\
\hline $\mathrm{C}_{2}$ & 1347 & 5045 & 58 & 58 & 3 & 2 & 154 & 204 & 3.3 & 2.7 & 2.8 & 2.4 & 6.3 \\
\hline $\mathrm{C}_{3}$ & 1443 & 5055 & 58 & 58 & 3 & 2 & 155 & 204 & 3.3 & 2.7 & 2.8 & 2.4 & 6.3 \\
\hline $\mathrm{P}_{2} \times$ Tester & 1156 & 5334 & 58 & 60 & 3 & 2 & 164 & 203 & 3.1 & 2.5 & 2.9 & 2.4 & 6.8 \\
\hline $\mathrm{P}_{1} \times$ Tester & 1317 & 6402 & 58 & 58 & 3 & 2 & 155 & 212 & 3.4 & 2.5 & 3.1 & 2.1 & 7.0 \\
\hline$P_{1} \times P_{2}$ & 1228 & 5752 & 59 & 59 & 4 & 2 & 165 & 221 & 3.4 & 2.3 & 2.8 & 2.1 & 6.3 \\
\hline 9022-13 (sus) & 323 & 2587 & 64 & 62 & 3 & 1 & 128 & 181 & 4.0 & 3.3 & 3.6 & 2.8 & 5.3 \\
\hline 8338-1(sus) & 1003 & 3174 & 63 & 62 & 2 & 2 & 163 & 197 & 3.6 & 3.5 & 2.9 & 2.6 & 5.3 \\
\hline $\operatorname{LSD}_{(0.05)}$ & ns & ns & ns & ns & ns & ns & $\mathrm{ns}$ & $\mathrm{ns}$ & $\mathrm{ns}$ & ns & 0.01 & $\mathrm{~ns}$ & $\mathrm{~ns}$ \\
\hline CV (\%) & 29 & 17 & 3 & 3 & 35 & 33 & 8 & 6 & 11 & 13 & 14 & 17 & 12 \\
\hline Gain cycle ${ }^{-1}$ & 44.9 & 6.0 & -0.02 & 0.11 & -0.1 & 0.03 & 0.9 & 0.9 & -0.03 & -0.03 & -0.06 & -0.03 & 0.02 \\
\hline$\%$ Resp cycle ${ }^{-1}$ & 3.6 & 0.1 & -0.03 & 0.2 & -2.9 & 1.5 & 0.6 & 0.4 & -0.9 & -1.1 & -2.0 & -1.2 & 0.3 \\
\hline$R^{2}$ & 0.71 & 0.04 & 0.07 & 0.69 & 0.07 & 0.60 & 0.36 & 0.60 & 0.60 & 0.60 & 0.60 & 0.60 & 0.07 \\
\hline
\end{tabular}

Resp, Response; Sus, Susceptible.

in the DS condition and also sustained a yield loss of $71 \%$ between the WW and DS conditions (Table 2). In general, mean ASI was 3 days under DS and 2 days under WW condition. Under Striga infestation, traits measured did not change with selection in the population through MARS. However, the testcrosses of $S_{1}$ lines derived from the various cycles produced more yield, had taller plants, supported fewer S. hermonthica plants, had improved Striga ratings and better EASP scores compared to the hybrid checks (Table 3 ).
The response to selection per cycle was $-2 \%$ for PASP under DS condition (Table 2).

Grain yield of the best testcrosses in each selected cycle of the MARS population under DS with their corresponding performance under WW condition, Striga infested and noninfested conditions are presented in Figure 1. The best testcrosses differed significantly from the parents, $\mathrm{P}_{1} \times \mathrm{P}_{2}$ and hybrid checks under DS condition. The performance of the testcrosses ranged from 35 to $84 \%$ above $\mathrm{P}_{1} \times \mathrm{P}_{2}$ and hybrid checks under DS 
TABLE 3 | Means and genetic gains for grain yield and other agronomic traits of testcrosses of a population improved with MARS under Striga infested condition at Abuja and Mokwa in 2014 and 2015.

\begin{tabular}{|c|c|c|c|c|c|c|c|c|}
\hline Genotypes & $\begin{array}{l}\text { Grain yield } \\
\left.\text { (kg ha }^{-1}\right)\end{array}$ & $\begin{array}{l}\text { Days to } \\
\text { silking }\end{array}$ & $\begin{array}{l}\text { Plant } \\
\text { height } \\
\text { (cm) }\end{array}$ & $\begin{array}{c}\text { Striga damage } \\
\text { rating } 8 \text { weeks } \\
(1-9)\end{array}$ & $\begin{array}{c}\text { Striga damage } \\
\text { rating } 10 \text { weeks } \\
(1-9)\end{array}$ & $\begin{array}{c}\text { Emerged Striga } \\
\text { count } 8 \text { weeks } \\
\text { (number) }\end{array}$ & $\begin{array}{c}\text { Emerged Striga } \\
\text { count } 10 \text { weeks } \\
\text { (number) }\end{array}$ & $\begin{array}{c}\text { Ear } \\
\text { aspect } \\
(1-5)\end{array}$ \\
\hline $\mathrm{C}_{0}$ & 3839 & 61 & 151 & 2.5 & 4.0 & 2.3 & 2.7 & 3.1 \\
\hline $\mathrm{C}_{1}$ & 4055 & 61 & 157 & 2.4 & 3.9 & 2.2 & 2.6 & 3.0 \\
\hline $\mathrm{C}_{2}$ & 4024 & 61 & 155 & 2.5 & 3.9 & 2.3 & 2.7 & 3.0 \\
\hline $\mathrm{C}_{3}$ & 3824 & 61 & 156 & 2.4 & 4.0 & 2.2 & 2.6 & 3.0 \\
\hline $\mathrm{P}_{2} \times$ Tester & 3220 & 62 & 155 & 2.6 & 4.1 & 2.1 & 2.8 & 3.1 \\
\hline $\mathrm{P}_{1} \times$ Tester & 3690 & 61 & 146 & 2.3 & 3.8 & 2.2 & 2.5 & 3.0 \\
\hline$P_{1} \times P_{2}$ & 4359 & 62 & 162 & 2.3 & 3.9 & 2.3 & 2.7 & 2.7 \\
\hline 9022-13 (tolerant) & 1371 & 66 & 144 & 3.5 & 6.5 & 2.6 & 3.1 & 3.6 \\
\hline 8338-1 (susceptible) & 406 & 57 & 126 & 5.1 & 6.7 & 2.7 & 2.9 & 4.6 \\
\hline $\operatorname{LSD}_{(0.05)}$ & 108 & 0.2 & 1.5 & ns & ns & ns & ns & ns \\
\hline CV (\%) & 20 & 4 & 7 & 21 & 20 & 31 & 23 & 12 \\
\hline Average gain cycle ${ }^{-1}$ & -7.6 & 0.07 & 1.3 & -0.02 & 0.03 & -0.02 & -0.02 & -0.03 \\
\hline$\%$ response cycle ${ }^{-1}$ & -0.2 & 0.1 & 0.9 & -0.8 & 0.6 & -0.9 & -0.7 & -1.0 \\
\hline$R^{2}$ & 0.01 & 0.52 & 0.41 & 0.20 & 0.12 & 0.20 & 0.20 & 0.60 \\
\hline
\end{tabular}

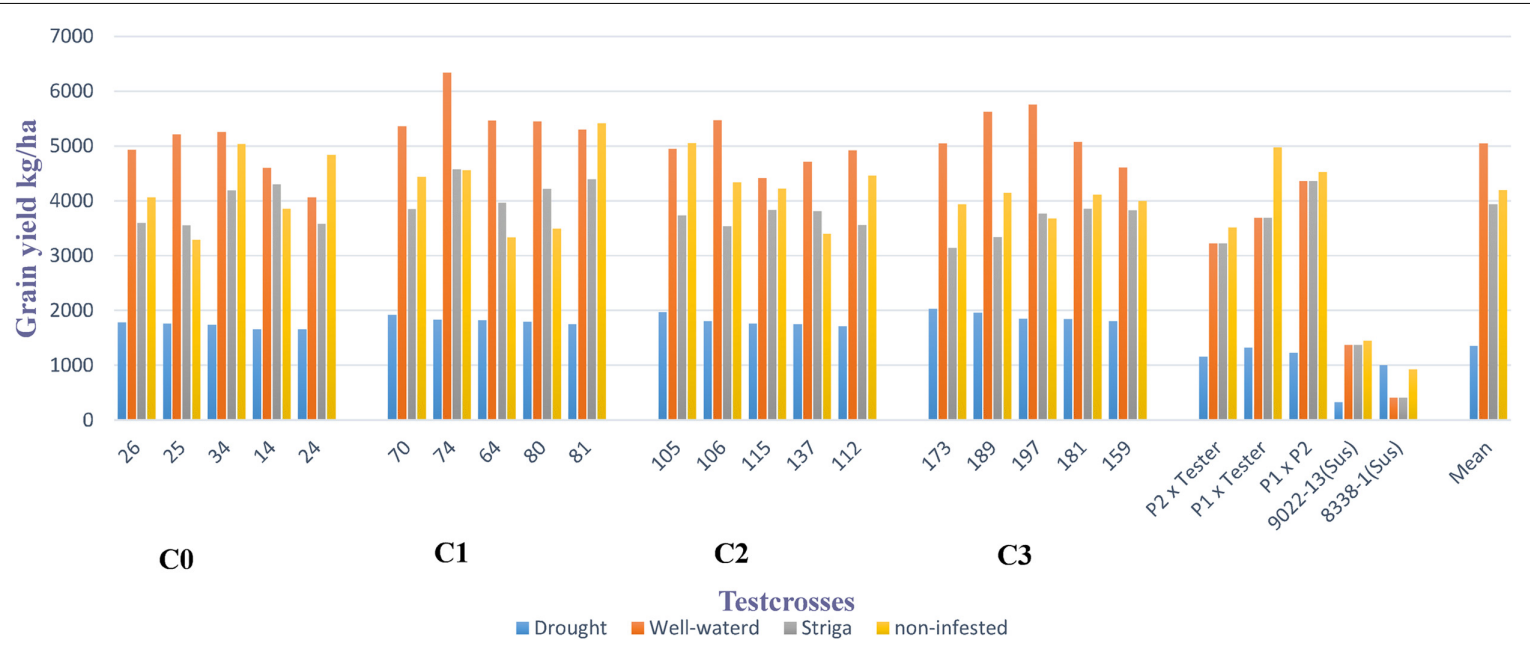

FIGURE 1 | Mean grain yield of the best five testcrosses selected from each cycle of MARS population under drought, well-watered, Striga infested and non-infested conditions at Ikenne, Abuja, and Mokwa in 2014 and 2015.

condition. However, the performance of the testcrosses above $\mathrm{P}_{1} \times \mathrm{P}_{2}$ and hybrid checks were not consistent under WW condition, Striga infested and non-infested conditions.

\section{Changes in Frequency of Favorable SNP Marker Alleles}

The mean frequency of the favorable marker alleles for grain yield increased from $C_{0}$ to $C_{3}$ by $9 \%$ (Table 4 ). In $C_{1}$, the frequencies of the favorable alleles fell below the expected frequency (0.50) and picked up again in the advanced cycles (Figure 2 and Table 4). None of the markers were fixed for the favorable allele in the different cycles of MARS (Table 4). The mean combination of favorable alleles present in each $\mathrm{S}_{1}$ lines increased significantly by $8 \%$ from $C_{0}$ to $C_{3}$ and the mean of the best $10 S_{1}$ lines cycle ${ }^{-1}$ increased from $\mathrm{C}_{0}$ to $\mathrm{C}_{3}$ by $7 \%$ (Table 5). The change in minor alleles decreased by $22 \%$ with advance in selection from $\mathrm{C}_{0}$ to $\mathrm{C}_{3}$, but none of the marker loci got fixed (Table 6). The level of heterozygosity among the cycles decreased by $15 \%$ and the number of effective alleles decreased by $9 \%$ from $\mathrm{C}_{0}$ to $\mathrm{C}_{3}$. The inbreeding coefficient increased by $57 \%$ and homozygosity by $13 \%$ from $\mathrm{C}_{0}$ to $\mathrm{C}_{3}$. About $5 \%$ of the total markers used were lost during selection at $\mathrm{C}_{2}$ and $\mathrm{C}_{3}$ (Table 7). Twelve genotypes were lost at $\mathrm{C}_{2}$ and $\mathrm{C}_{3}$ and only two of the markers (bt2_7 and PZA02148_1) were common in the two cycles (Table 7).

\section{DISCUSSION}

Developing hybrids that are able to withstand DS throughout the growing season with no yield penalty under optimum conditions have become important, since drought incidence and severity 
TABLE 4 | Means, maximum, and minimum frequencies of favorable marker alleles for yield.

\begin{tabular}{lcccc}
\hline Cycles & $\mathbf{C}_{\mathbf{0}}$ & $\mathbf{C}_{\mathbf{1}}$ & $\mathbf{C}_{\mathbf{2}}$ & $\mathbf{C}_{\mathbf{3}}$ \\
\hline Minimum & 0.33 & 0.23 & 0.19 & 0.08 \\
Maximum & 0.76 & 0.80 & 0.95 & 0.91 \\
Skewness & 0.86 & 0.21 & 0.21 & 0.16 \\
Kurtosis & 3.49 & -0.63 & -0.67 & -0.35 \\
Mean & $0.50 \pm 0.01$ & $0.49 \pm 0.01$ & $0.52 \pm 0.01$ & $0.55 \pm 0.01$ \\
\hline
\end{tabular}

vary considerably among years and within fields (Beyene et al., 2016a). The year $\times$ cycle interaction was not significant for any of the measured traits under both DS and WW conditions, suggesting that cycles showed consistent performance despite the stress conditions, across the 2 years. This was consistent with the result of other authors (Menkir and Kling, 2007; Derera et al., 2008; Menkir et al., 2010; Adebayo and Menkir, 2014) but was in disagreement with Menkir et al. (2012). Consequently, genotypes with consistently better drought tolerance and high yield potential can be selected under both conditions.

The absence of significance among cycles and the high level of yield reduction observed in this study under DS condition, resulted from the combined effect of severe DS and armyworm (Spodoptera spp.) infestation that occurred in 2015. DS can cause detrimental effects to plant pathogen resistance (Atkinson and Urwin, 2012). Exposure of plants to a pest or pathogen increases the effects of an abiotic stress such as water deficit (Cockfield and Potter, 1986; Audebert et al., 2000). For these reasons, the observed yield reduction under DS in the present study was more than those reported by other authors (NeSmith and Ritchie, 1992; Banziger et al., 2000; Menkir and Akintunde, 2001; Campos et al., 2006; Derera et al., 2008). Though, an increase in mean performance for grain yield, plant height and a decrease in PASP and SEN ware observed in the bi-parental population, the observed shift with selection moved towards the positive direction. This was consistent with the result of Beyene et al.
(2015), who also reported an increase in grain yield and plant height. The ASI increased up to 4 days under DS condition from an average of 2 days under WW condition. These results are in agreement with the findings of earlier studies (Edmeades et al., 1995; Menkir and Akintunde, 2001; Kamara et al., 2003), who reported that ASI is a useful adaptive trait for selecting maize for drought-tolerance. Days to silking did not differ for all cycles, indicating that the lines were at similar phenological stage (Magorokosho et al., 2003). MARS cycles for plant height and SEN were significantly $(P<0.05)$ different from each other and from the hybrid checks. Beyene et al. (2016a) also found significant difference among the populations for plant height under DS.

The non-significant gain for grain yield observed in this study under DS, was not consistent with the findings of previous empirical and simulation studies (Bernardo and Yu, 2007; Massman et al., 2013; Beyene et al., 2016a). The lack of response to selection under WW condition for grain yield and other traits was consistent with the findings of previous studies (Bänziger et al., 1999; Magorokosho et al., 2003). Beyene et al. (2015) and Semagn et al. (2015) conducted MARS on different bi-parental maize populations under DS and WW environments and observed that each population deferred in their response to MARS.

The focus of MARS on selection for high yield under managed DS alone did not result in an overall improvement in genetic gain for grain yield and resistance to the parasite. Nonetheless, the selection for tolerance to drought did not have any negative effect on the performance of testcrosses of the different selection cycles when compared to the parents and hybrid checks. As selection for drought tolerance resulted in a negative response to selection for grain yield under Striga infestation (non-target traits), it is important to choose parents with tolerance to multiple stress and conduct selection under the different stress conditions to attain the desirable improvement in performance of the progenies derived from bi-parental cross. This was in agreement with the findings of Casler et al. (2003), who reported little improvement on the non-target trait from the simultaneous improvement

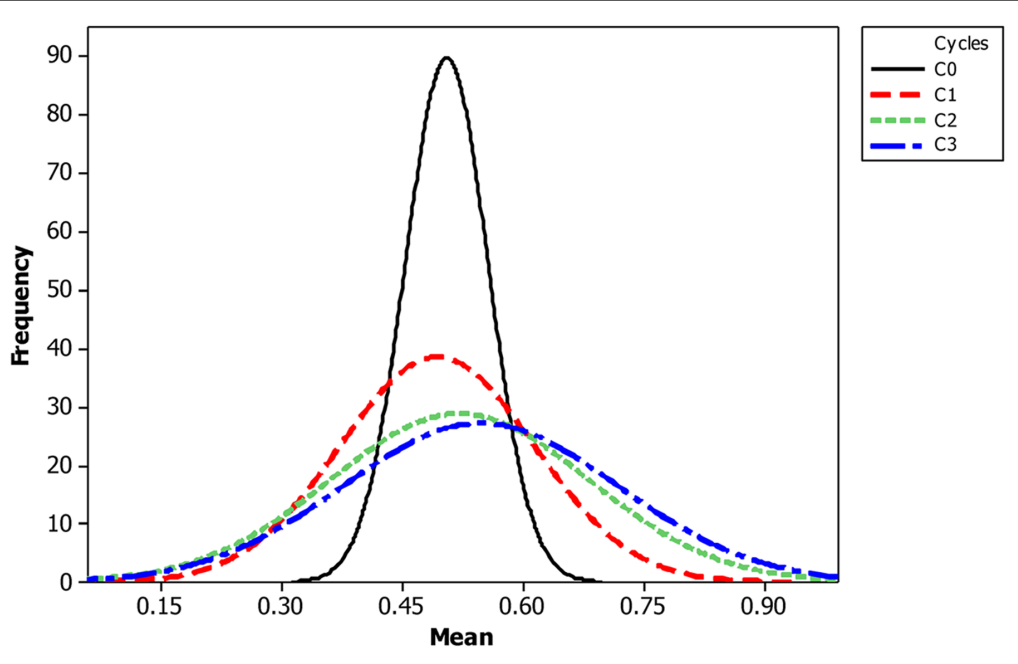

FIGURE 2 | Changes in frequency of favorable alleles from $\mathrm{CO}$ to $\mathrm{C} 3$ in the bi-parental population. 
TABLE 5 | Means, maximum, and minimum number of combinations of favorable marker alleles present in all and the best $10 \mathrm{~S}_{1}$ lines of each MARS cycle.

\begin{tabular}{lccc}
\hline Entries & $\begin{array}{c}\text { Minimum } \\
\text { favorable } \\
\text { alleles in } \mathbf{S}_{\mathbf{1}}\end{array}$ & $\begin{array}{c}\text { Maximum } \\
\text { favorable } \\
\text { alleles in } \mathbf{S}_{\mathbf{1}}\end{array}$ & $\begin{array}{c}\text { Mean of } \\
\text { favorable } \\
\text { alleles in } \mathbf{S}_{\mathbf{1}}\end{array}$ \\
\hline $\mathrm{C}_{0} \mathrm{~S}_{1}$ lines & 54 & 132 & $114 \pm 1.6$ \\
Best $10 \mathrm{C}_{0} \mathrm{~S}_{1}$ lines & 125 & 132 & $128 \pm 1.0$ \\
$\mathrm{C}_{1} \mathrm{~S}_{1}$ lines & 8 & 132 & $111 \pm 2.1$ \\
Best $10 \mathrm{C}_{1} \mathrm{~S}_{1}$ lines & 124 & 132 & $128 \pm 1.0$ \\
$\mathrm{C}_{2} \mathrm{~S}_{1}$ lines & 86 & 138 & $117 \pm 1.3$ \\
Best $10 \mathrm{C}_{2} \mathrm{~S}_{1}$ lines & 127 & 138 & $130 \pm 1.3$ \\
$\mathrm{C}_{3} \mathrm{~S}_{1}$ lines & 87 & 145 & $124 \pm 1.5$ \\
Best $10 \mathrm{C}_{3} \mathrm{~S}_{1}$ lines & 134 & 145 & $138 \pm 1.0$ \\
\hline
\end{tabular}

of forage yield and seed yield of orchard grass bred for an increase in forage yield. Contrary to these findings, Lafitte and Edmeades (1995) and Edmeades et al. (2006), reported significant improvements in the non-target trait in a research selected for tolerance to drought. These could probably be due to genetic and physiological mechanism(s) between the parental traits. In rare situations, selection for a non-target trait proves more effective than the target trait and when it occurs, it may simply be that the parental alleles under selection are more or less the same in both environments or because the environments do not differ sufficiently (Witcombe et al., 2008).

Testcrosses 14, 34, 64, 74, 80, and 81 showed consistent performance above the mean under both DS and Striga infested conditions. As shown in Figure 1, the best testcrosses derived from the bi-parental cross produced higher mean grain yields than the parents, $\mathrm{P}_{1} \times \mathrm{P}_{2}$ and hybrid checks under DS condition. This result is similar to the findings of Beyene et al. (2016b), who reported higher performance in grain yield of MARS derived lines compared to parents and hybrid checks under DS condition.

The increase in mean frequency of the favorable marker alleles for grain yield from $C_{0}$ to $C_{3}$ indicated that MARS rapidly accumulates favorable alleles linked to the desired QTLs in the breeding population while decreasing the frequency of the unfavorable alleles (Hallauer, 1985; Hallauer and Miranda, 1988; Mhike et al., 2010). Our result is in agreement with Bernardo and Mayor (2009), who reported an increase in frequency of favorable marker alleles for grain yield, grain moisture, plant integrity, and stay green in a $\mathrm{DH}$ mapping population improved using MARS. Edwards and Johnson (1994), also reported an increase in the frequency of favorable alleles in an $\mathrm{F}_{2}$ population of sweet corn improved using MARS with some marker loci fixed for the favorable alleles. The frequency of alleles with large effects should
TABLE 7 | The loss of genotypes in SNP markers across MARS cycles.

\begin{tabular}{lllll}
\hline Markers & $\mathbf{C}_{0}$ & $\mathbf{C}_{\mathbf{1}}$ & $\mathbf{C}_{2}$ & $\mathbf{C}_{\mathbf{3}}$ \\
\hline bt2_4 & ++ & ++ & ++ & $\mathrm{A} / \mathrm{A}$ \\
bt2_7 & ++ & ++ & $\mathrm{G} / \mathrm{G}$ & $\mathrm{G} / \mathrm{G}$ \\
PHM1190_3 & ++ & ++ & ++ & $\mathrm{A} / \mathrm{A}$ \\
PHM3334_4 & ++ & ++ & ++ & $\mathrm{G} / \mathrm{G}$ \\
PHM3334_6 & ++ & ++ & ++ & $\mathrm{G} / \mathrm{G}$ \\
PHM3587_6 & ++ & ++ & ++ & $\mathrm{G} / \mathrm{G}$ \\
PZA00311_5 & ++ & ++ & ++ & $\mathrm{A} / \mathrm{A}$ \\
PZA00613_22 & ++ & ++ & ++ & $\mathrm{C} / \mathrm{C}$ \\
PZA02148_1 & ++ & ++ & $\mathrm{G} / \mathrm{G}$ & $\mathrm{G} / \mathrm{G}$ \\
PZA02260_2 & ++ & ++ & ++ & $\mathrm{C} / \mathrm{C}$ \\
PZA03270_2 & ++ & ++ & ++ & $\mathrm{A} / \mathrm{A}$ \\
PZA03597_1 & ++ & ++ & ++ & $\mathrm{A} / \mathrm{A}$ \\
\hline ++, Genotype is present in the cycle; $\mathrm{A} / \mathrm{A}$, G/G, C/C, missing genotypes. &
\end{tabular}

increase or decrease faster than the frequency of alleles with relatively small effects (Delaney and Bliss, 1991). The trajectory of change in allele frequency allows for the identification of favorable, neutral, or unfavorable alleles. On the other hand, Johnson (2004) found a high mean frequency at $C_{1}$ while a third population showed no difference in mean frequency of favorable alleles between $C_{1}$ and $C_{2}$. Our results suggest that breeder may conduct three cycles of MARS to develop superior inbred lines for evaluation.

The mean combination of favorable alleles present in the present study reveals that all the $S_{1}$ lines derived from the advanced cycle $\left(\mathrm{C}_{3}\right)$, had more combinations of favorable alleles than those derived from $\mathrm{C}_{0}$, suggesting that a lot of recombination had taken place and the breeding scheme was effective in enhancing genetic gain in the bi-parental population. The observed increase in inbreeding coefficient with selection are in agreement with Dorak (2014), who stated that positive inbreeding coefficient values indicates heterozygote deficiency compared with Hardy-Weinberg Equilibrium expectations. The high rate of loss of heterozygosity in the MARS populations was also an indicator of the effect of selection. The frequency of heterozygotes at the marker loci shown in MARS cycles decreased as the selection progressed, which was consistent with the findings of Massman et al. (2013), who also observed loss of heterozygosity in testcrosses of B73 $\times$ Mo17 MARS population using SNP markers. The unequal percentage decrease in heterozygosity and increase in homozygosity was due to loss of some genotypes in their homozygous state. The loss of genotypes observed in this study suggests that desirable alleles were selected throughout the four selection cycles. The fact that no genotype was gained throughout the selection process in each cycle

TABLE 6 | Allelic pattern of MARS population genotyped using single nucleotide polymorphism (SNP) markers.

\begin{tabular}{lccccc}
\hline Cycles & Minor allele frequency & Inbreeding coefficient & Heterozygosity & Homozygosity & Number of effective alleles \\
\hline $\mathrm{C}_{0}$ & 0.46 & 0.03 & 0.48 & 0.52 & 1.98 \\
$\mathrm{C}_{1}$ & 0.40 & 0.04 & 0.45 & 0.55 & 1.90 \\
$\mathrm{C}_{2}$ & 0.37 & 0.06 & 0.42 & 0.58 & 1.83 \\
$\mathrm{C}_{3}$ & 0.36 & 0.07 & 0.41 & 0.60 & 1.81
\end{tabular}


provides further evidence that the genotypic data was accurately scored and is a true representation of the genetic changes that occurred during breeding cycles. A similar result was observed by Vogel (2010) in characterization of maize populations selected for grain methionine content using SNP markers. Further research is needed on the use of haplotype signatures to identify genomic regions that have responded to selection.

\section{CONCLUSION}

The MARS procedure caused desirable changes in frequency of favorable marker alleles, though no significant gain in grain yield was recorded under DS condition due to the severe fall armyworm infestation. The absence of changes in grain yield from the original to the advanced selection cycles under Striga infestation could arise from the fact that the selection has not been done to improve defensive traits against Striga. Our study demonstrated that selection for improved performance under DS did not necessarily have a negative effect on grain yield under WW conditions and also, selection of parents with tolerance to multiple stress may allow some acceptable level of resistance to the parasite even when improvements were made only for tolerance to drought. To make significant progress from selection, however, selection for multiple stress should be done simultaneously under the target stress conditions. MARS could therefore, be used to improve genetic gains for complex traits like drought and accelerate the development of new inbred lines in maize breeding programs.

\section{AUTHOR CONTRIBUTIONS}

MG have contributed in the genotyping and cycling by GEBV selection as well as review of the manuscript; AM

\section{REFERENCES}

Abdulmalik, R. O., Menkir, A., Gedil, M., Ado, S. G., Olarewaju, J. D., Aba, D. A., et al. (2016). "Genetic gains in bi-parental population improved through marker assisted recurrent selection under drought stress," in Proceedings of the Abstracts of the 20th EUCARPIA General Congress, Zurich, 40.

Adebayo, M. A., and Menkir, A. (2014). Assessment of hybrids of drought tolerant maize (Zea mays L.) inbred lines for grain yield and other traits under stress managed conditions. Niger. J. Genet. 28, 19-23. doi: 10.1016/j.nigjg.2015. 06.004

Adetimirin, V. O., Vroh-Bi, C., Menkir, A., Mitchell, S. E., and Kresovich, S. (2008). Diversity analysis of elite maize inbred lines adapted to West and Central Africa using SSR markers. Maydica 53, 143-149.

Atkinson, N. J., and Urwin, P. E. (2012). The interaction of plant biotic and abiotic stresses: from genes to the field. J. Exp. Bot. 63, 3523-3543. doi: 10.1093/jxb/ ers 100

Audebert, A., Coyne, D. L., Dingkuhn, M., and Plowright, R. A. (2000). The influence of cyst nematodes (Heterodera sacchari) and drought on water relations and growth of upland rice in Cote d'Ivoire. Plant Soil 220, 235-242. doi: 10.1023/A:1004734415254

Azmach, G., Gedil, M., Menkir, A., and Spillane, C. (2013). Marker-trait association analysis of functional gene markers for pro-vitamin A levels across diverse tropical yellow maize inbred lines. BMC Plant Biol. 13:227. doi: 10.1186/14712229-13-227 contributed in the breeding conception of the work, edited, critically reviewed, and gave final approval of the version of the manuscript; SM, SA, JO, and DA also reviewed the manuscript; NU contributed in the genotypic selection of the work; $\mathrm{SH}$ designed and optimized the experiment; JC performed biometric analysis of the parental and $F_{2}$ generation; and RA analyzed, interpreted the data, and wrote the manuscript.

\section{FUNDING}

This study is part of a Ph.D. research thesis Funded by the Bill and Melinda Gates Foundation Grant No. OPP1006185-1 to International Institute of Tropical Agriculture (IITA), under the Project "Achieving sustainable Striga control for poor farmers in Africa, Integrated Striga Management in Africa (ISMA) and Drought Tolerant Maize for Africa (DTMA).”

\section{ACKNOWLEDGMENTS}

The authors acknowledge the significant support of Dr. M. Oluoch, Dr. W. Mengesha, Y. Fasanmade, Prof. R. Bernardo, IITA field technicians in Nigeria, CIMMYT breeders and field technicians at the different experimental stations in Kenya and Zimbabwe.

\section{SUPPLEMENTARY MATERIAL}

The Supplementary Material for this article can be found online at: http://journal.frontiersin.org/article/10.3389/fpls.2017.00841/ full\#supplementary-material

Banziger, M., Edmeades, G. O., Beck, D., and Bellon, M. (2000). Breeding for Drought and Nitrogen Stress Tolerance in Maize: From Theory to Practice. Mexico: CIMMYT.

Bänziger, M., Edmeades, G. O., and Lafitte, H. R. (1999). Selection for drought tolerance increases maize yields across a range of nitrogen levels. Crop Sci. 39, 1035-1040. doi: 10.2135/cropsci1999.0011183X003900040012x

Bernardo, R., and Mayor, P. J. (2009). Doubled haploids in commercial maize breeding: one-stage and two-stage phenotypic selection versus marker-assisted recurrent selection. Maydica 54, 439-448.

Bernardo, R., and Yu, J. M. (2007). Prospects for genomewide selection for quantitative traits in maize. Crop Sci. 47, 1082-1090. doi: 10.2135/cropsci2006. 11.0690

Beyene, Y., Semagn, K., Crossa, J., Mugo, S., Gary, N., Tarekegne, A., et al. (2016a). Improving maize grain yield under drought stress and non-stress environments in sub-Saharan Africa using marker-assisted recurrent selection. Crop Sci. 56, 344-353. doi: 10.2135/cropsci2015.02.0135

Beyene, Y., Semagn, K., Mugo, S., Prasanna, B. M., Tarekegne, A., Gakunga, J., et al. (2016b). Performance and grain yield stability of maize populations developed using marker-assisted recurrent selection and pedigree selection procedures. Euphytica 208, 285-297. doi: 10.1007/s10681-015-1590-1

Beyene, Y., Semagn, K., Mugo, S., Tarekegne, A., Babu, R., Meisel, B., et al. (2015) Genetic gains in grain yield through genomic selection in eight bi-parental maize populations under drought stress. Crop Sci. 55, 154-163. doi: 10.2135/ cropsci2014.07.0460 
Bohra, A. (2013). Emerging paradigms in genomics-based crop improvement. ScientificWorldJournal 2013:585467. doi: 10.1155/2013/585467

Campos, H., Cooper, M., Edmeades, G. O., Loffer, C., Schusssler, J. R., and Ibanez, M. (2006). Changes in drought tolerance in maize associated with fifty years of breeding for yield in the US corn-belt. Maydica 51, 369-381.

Casler, M. D., Barker, R. E., Brummer, E. C., Papadopolous, Y. A., and Hoffman, L. D. (2003). Selection for orchard grass seed yield in target vs. non-target environments. Crop Sci. 43, 532-538. doi: 10.2135/cropsci2003.5320

Charmet, G., Robert, N., Perretant, M. R., Gay, G., Sourdille, P., Groos, C., Bernard, S. and Bernard, M. (1999). Marker-assisted recurrent selection for cumulating additive and interactive QTLs in recombinant inbred lines. Theor. Appl. Genet. 99, 1143-1148. doi: 10.1007/s001220051318

Cockfield, S. D., and Potter, D. A. (1986). Interaction of Euonymus scale (homoptera: diaspididae) feeding damage and severe water stress on leaf abscission and growth of Euonymus fortunei. Oecologia 71, 41-46. doi: 10.1007/ BF00377318

Crossa, J., Beyene, Y., Kassa, S., Pérez, P., Hickey, J. M., Chen, C., et al. (2013). Genomic prediction in maize breeding populations with genotyping-bysequencing. G3 3, 1903-1926. doi: 10.1534/g3.113.008227

Cruz, I., Figueiredo, M. L. C., Oliveira, A. C., and Vasconcelos, C. A. (1999). Damage of Spodoptera frugiperda (Smith) in different maize genotypes cultivated in soil under three levels of aluminium saturation. Inter. J. Pest Manag. 45, 293-296. doi: 10.1080/096708799227707

Delaney, D. E., and Bliss, F. A. (1991). Selection for increased percentage phaseolin in common bean: 2 . Changes in frequency of seed protein alleles with $\mathrm{S} 1$ family recurrent selection. Theor. Appl. Genet. 81, 306-312. doi: 10.1007/BF00228668

Derera, J., Tongoona, P., Vivek, B. S., and Laing, M. D. (2008). Gene action controlling grain yield and secondary traits in southern African maize hybrids under drought and non-drought environments. Euphytica 162, 411-422. doi: 10.1007/s10681-007-9582-4

Dorak, M. T. (2014). Basic Population Genetics. Available at: www.dorak.info/ genetics/popgen.html [accessed April 18, 2014].

Eathington, S. R., Crosbie, T. M., Edwards, M. D., Reiter, R. S., and Bull, J. K. (2007). Molecular markers in a commercial breeding program. Crop Sci. 47, 154-163. doi: 10.2135/cropsci2007.04.0015IPBS

Edmeades, G. O. (2008). "Drought tolerance in maize: An emerging reality," in Global Status of Commercialized Biotechnology/GM Crops, ed. C. James (Ithaca, NY: ISAAA), 1-12.

Edmeades, G. O. (2013). Progress in Achieving and Delivering Drought Tolerance in Maize-An Update. Ithaca, NY: International Service for the Acquisition of Agri-Biotech Applications.

Edmeades, G. O., Bänziger, M., Campos, H., and Schussler, J. (2006). "Improving tolerance to abiotic stresses in staple crops: a random or planned Process?, in Proceedings of the Plant breeding: the Arnel R. Hallauer International Symposium, eds K. R. Lamkey and M. Lee (Ames, IA: Blackwell Publishing), 293-309. doi: 10.1002/9780470752708.ch21

Edmeades, G. O., Bolanos, J., Chapman, S. C., Lafitte, H. R., and Bänziger, M. (1999). Selection improves drought tolerance in tropical maize populations: I. Gains in biomass, grain yield, and harvest index. Crop Sci. 39, 1306-1315. doi: 10.2135/cropsci1999.3951306x

Edmeades, G. O., Chapman, S. C., Bänziger, M., and Deutsch, J. A. (1995). CIMMYT Maize Drought Tolerance Network: Report. Mexico: CIMMYT.

Edwards, M., and Johnson, L. (1994). "RFLPs for rapid recurrent selection," in Proceedings of the Analysis of Molecular Marker Data. Joint Plant Breeding. Symposium Series of American Society for Horticultural Science and CSSA, Madison, 33-40.

Frascaroli, E., and Landi, P. (1998). Allelic frequency changes of P1 gene in a maize population after recurrent selection for grain yield. Crop Sci. 38, 1391-1394. doi: 10.2135/cropsci1998.0011183X003800050039x

Gianola, D., and Fernando, R. L. (1986). Bayesian methods in animal breeding theory. J. Anim. Sci. 63, 217-244. doi: 10.2527/jas1986.631217x

Hallauer, A. H. (1985). Compendium of recurrent selection methods and their application. Crit. Rev. Plant Sci. 3, 1-33. doi: 10.1080/07352688509382202

Hallauer, A. R., and Miranda, J. B. (1988). Quantitative Genetics in Maize Breeding. Ames, IA: Iowa State University Press.

Henderson, C. R. (1975). Best linear unbiased estimation and prediction under a selection model. Biometrics 31, 423-447. doi: 10.2307/2529430
Hospital, F., Moreau, L., Lacoudre, F., Charcosset, A., and Gallais, A. (1997). More on the efficiency of marker-assisted selection. Theor. Appl. Genet. 95, 1181-1189. doi: 10.1007/s001220050679

Johnson, L. (2001). "Marker assisted sweet corn breeding: a model for specialty crops," in Proceedings of 56th Annual Corn and Sorghum Industry Research Conference, Vol. 56, Chicago, IL, 25-30.

Johnson, R. (2004). Marker-assisted selection. Plant Breed. Rev. 24, 293-310.

Kamara, A. Y., Menkir, A., Badu-Apraku, B., and Ibikunle, O. (2003). The influence of drought on growth, yield and yield components of selected maize genotypes. J. Agric. Sci. 141, 43-50. doi: 10.1017/S0021859603003423

Khalil, I. A., Durres, H., Nawaz, I., Ullah, H., and Ali, F. (2010). Response to selection for grain yield under maydis leaf blight stress environment in maize (Zea mays). Biol. Divers. Conserv. 3, 121-127.

Kim, S. K. (ed.). (1991). "Breeding maize for Striga tolerance and the development of a field infestation technique," in Combating Striga in Africa. (Ibadan: IITA), 96-108.

Lafitte, H. R., and Edmeades, G. O. (1995). Stress tolerance in tropical maize is linked to constitutive changes in ear growth characteristics. Crop Sci. 35, 820-826. doi: 10.2135/cropsci1995.0011183X003500030031x

Lagoke, S. T. O., Parkinson, V., and Agunbiade, R. M. (1991). "Parasitic weed control methods in Africa," in Proceedings in International Workshop (IITA, ICRISAT and IDRC): Combating Striga in Africa, Ibadan, Nigeria 22-24 August 1998, ed. S. K. Kim (Ibadan: IITA), 3-14.

Lima, M. S., Silva, P. S. L., Oliveira, O. F., Silva, K. M. B., and Freitas, F. C. L. (2010). Corn yield response to weed and fall armyworm controls. Planta Daninha 28, 103-111. doi: 10.1590/S0100-83582010000100013

Magorokosho, C., Pixley, K. V., and Tongoona, P. (2003). Selecting for drought tolerance in two tropical maize populations. Afr. Crop Sci. J. 11, 151-161.

Massman, J. M., Jung, H.-J. G., and Bernardo, R. (2013). Genomewide selection versus marker-assisted recurrent selection to improve grain yield and stoverquality traits for cellulosic ethanol in maize. Crop Sci. 53, 58-66. doi: 10.2135/ cropsci2012.02.0112

Menkir, A., and Akintunde, A. O. (2001). Evaluation of the performance of maize hybrids, improved open-pollinated and farmers' local varieties under well watered and drought stress conditions. Maydica 46, 227-238.

Menkir, A., Chikoye, D., and Lum, F. (2010). Incorporating an herbicide resistance gene into tropical maize with inherent polygenic resistance to control Striga hermonthica (Del.) Benth. Plant Breed. 129, 385-392. doi: 10.1111/j.1439-0523. 2009.01687.x

Menkir, A., and Kling, J. G. (2007). Response to recurrent selection for resistance to Striga hermonthica (Del.) Benth in a tropical maize population. Crop Sci. 47, 674-684. doi: 10.2135/cropsci2006.07.0494

Menkir, A., Makumbi, D., and Franco, J. (2012). Assessment of reaction patterns of hybrids to Striga hermonthica (Del.) Benth. under Artificial Infestation in Kenya and Nigeria. Crop Sci. 52, 2528-2537. doi: 10.2135/cropsci2012. 05.0307

Meuwissen, T. H. E., Hayes, B. J., and Goddard, M. E. (2001). Prediction of total genetic value using genome -wide dense marker maps. Genetics 157, 1819-1829.

Mhike, X., Okori, P., and Magorokosho, C. (2010). "Genetic inheritance studies and early generation Marker selection in maize breeding for drought tolerance," in Proceeding of the Second Ruforum Biennial Meeting 20-24th September, Entebbe, 389-393.

Mhike, X., Okori, P., Magorokosho, C., and Ndhlela, T. (2012). Validation of the use of secondary traits and selection indices for drought tolerance in tropical maize (Zea mays L.). Afr. J. Plant Sci. 6, 96-102. doi: 10.5897/AJPS11.179

NeSmith, D. S., and Ritchie, J. T. (1992). Effects of water-deficits during tassel emergence on development and yield components of maize (Zea mays L.). Field Crops Res. 28, 251-256. doi: 10.1016/0378-4290(92)90044-A

Odendo, M., De Groote, H., and Odongo, O. M. (2001). “Assessment of Farmers' Preferences and constraints to maize Production in the moist mid-altitude zone of Western Kenya," in Proceedings of the African Crop Science Conference, Kampala, 769-775.

Odhiambo, G., and Woomer, P. L. (2005). "Striga emergence and seed bank dynamics under different maize management practices in Western Kenya," in Proceedings of the African Crop Science Conference, Vol. 7, eds J. S. Tenywa, E. Adipala, P. Nampala, G. Tusiime, P. Okori, and W. Kyamuhangire (Kampala: African Crop Science Society), 473-477. 
Prasanna, B. M., Cairns, J., and Xu, Y. (2013). "Genomic tools and strategies for breeding climate resilient cereals," in Genomics and Breeding for Climate Resilient Crops. Concepts and Strategies, ed. C. Kole (Berlin: Springer-Verlang), 213-239. doi: 10.1007/978-3-642-37045-8_5

SAS Institute (2009). Statistical Analysis Software (SAS) User's Guide 9.3. Cary, NC: SAS Institute, Inc.

Semagn, K., Beyene, Y., Babu, R., Nair, S., Gowda, M., Das, B., et al. (2015). Quantitative trait loci mapping and molecular breeding for developing stress resilient maize for sub-Saharan Africa. Crop Sci. 55:1. doi: 10.2135/cropsci2014. 09.0646

Semagn, K., Beyene, Y., Warburton, M. L., Tarekegne, A., Mugo, S., Meisel, B., et al. (2013). Meta-analyses of QTL for grain yield and anthesis silking interval in 18 maize populations evaluated under water-stressed and well-watered environments. BMC Genomics 14:313. doi: 10.1186/1471-2164-14-313

Van Berloo, R., and Stam, P. (1998). Marker-assisted selection in autogamous RIL populations: A simulation study. Theor. Appl. Genet. 96, 147-154. doi: $10.1007 / \mathrm{s} 001220050721$

Van Berloo, R., and Stam, P. (2001). Simultaneous marker-assisted selection for multiple traits in autogamous crops. Theor. Appl. Genet. 102, 1107-1112. doi: $10.1007 / \mathrm{s} 001220000518$

Vogel, K. E. (2010). Genetic Characterization of Maize Populations Selected for Grain Methionine Content. Graduate theses, Iowa State University, Iowa.
Witcombe, J. R., Hollington, P. A., Howarth, C. J., Reader, S., and Steele, K. A. (2008). Breeding for abiotic stresses for sustainable agriculture. Philos. Trans. Royal Soc. Lond. B Biol. Sci. 363, 703-716. doi: 10.1098/rstb.2007. 2179

Xu, Y., Lu, Y., Xie, C., Gao, S., Wan, J., and Prasanna, B. M. (2012). Wholegenome strategies for marker-assisted plant breeding. Mol. Breed. 29, 833-854. doi: 10.1007/s11032-012-9699-6

Yousef, G. G., and Juvik, J. A. (2001). Comparison of phenotypic and markerassisted selection for quantitative traits in sweet corn. Crop Sci. 41, 645-655. doi: $10.2135 /$ cropsci2001.413645x

Conflict of Interest Statement: The authors declare that the research was conducted in the absence of any commercial or financial relationships that could be construed as a potential conflict of interest.

Copyright (c) 2017 Abdulmalik, Menkir, Meseka, Unachukwu, Ado, Olarewaju, Aba, Hearne, Crossa and Gedil. This is an open-access article distributed under the terms of the Creative Commons Attribution License (CC BY). The use, distribution or reproduction in other forums is permitted, provided the original author(s) or licensor are credited and that the original publication in this journal is cited, in accordance with accepted academic practice. No use, distribution or reproduction is permitted which does not comply with these terms. 